\title{
ISOLATION AND STRUCTURE ELUCIDATION OF TWO NEW CALPAIN INHIBITORS FROM Streptomyces griseus
}

\author{
M. Estela Alvarez*, David R. Houck, Carole B. White, James E. Brownell, \\ Mark A. Bobko, Charles A. Rodger, Mary B. Stawicki, Hao H. Sun,
}

Amanda M. Gillum and Raymond CoOper.

Sterling Winthrop Pharmaceutical Research Division, 25 Great Valley Parkway, Malvern, PA 19355, U.S.A.

(Received for publication May 26, 1994)

\begin{abstract}
Two new peptides, a diketopiperazine of $N$-methyltyrosine (1) and a tetrapeptide containing $N$-methyltyrosine (2), were isolated from an actinomycete strain Streptomyces griseus. These compounds inhibit the enzyme calpain in the micromolar range and were characterized on the basis of spectroscopic analysis, amino acid analysis and sequencing. The structure of the tetrapeptide $N$-methyltyrosyl- $N$-methyltyrosyl-leucyl-alanine (2), was also confirmed by total synthesis.
\end{abstract}

Calpain is a cytosolic cysteine protease regulated by $\mathrm{Ca}^{2+}$ widely distributed in mammalian and avian cells $^{1}$. Its function is to catalyze proteolysis of target proteins in cells, causing significant changes in metabolic processes ${ }^{2)}$ such as activation of protein kinase $\mathrm{C}$, neuropeptide metabolism and activation of platelets ${ }^{3)}$. Calpain inhibitors have been isolated from the tissues of a variety of animals, plants and culture fluids of microbes. The biological significance of these inhibitors has been investigated because of their therapeutic effects ${ }^{2}$. These inhibitors can be used for the treatment of neurodegenerative diseases since they also prevent neuronal cell loss.

In our natural products program screening for calpain inhibitors from microbial sources, an actinomycete strain, Streptomyces griseus (SC488), exhibited activity in the calpain assay. In this paper the isolation, structure elucidation and activity of two novel calpain inhibitors are described.

\section{Materials and Methods}

General Experimental Procedures

High performance liquid chromatography (HPLC) was performed on an HPLC Waters 991 with a photodiode array detector. HPLC grade solvents (OmniSolv) were used for chromatographic separations.

Fig. 1. Structures of compounds isolated from actinomycete SC488.

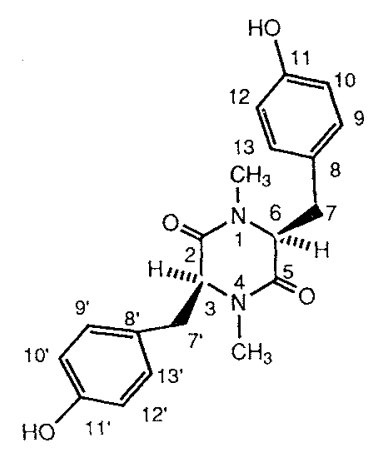

Diketopiperazine of $N$-methyltyrosine 1<smiles>[Y2]c1ccc(O)cc1C[C@H](C(=O)N[C@H](CC(C)C)C(=O)NC(C)C(=O)O)N(C)C(=O)[C@@H](Cc1ccc(O)cc1)NC</smiles>

$N$-Methyltyrosyl- $N$-methyltyrosyl-leucyl-alanine 2 
Solvents were filtered and degassed prior to use.

Mass spectrometry (MS) was performed on a Finnigan MAT TSQ 70 Spectrometer (MS/MS), Kratos Profile Magnetic Sector (FAB MS) and VG Analytical ZAB 2-SE high field.

CD curves were measured on a JASCO J-600 spectropolarimeter. UV traces were recorded on a Shimadzu UV160U spectrometer. IR spectra were recorded on a Nicolet 550 Magna IR.

NMR spectra were recorded at $300 \mathrm{~K}$ on a Bruker AMX spectrometer system equipped with a standard multinuclear probehead operating at $500.13 \mathrm{MHz}$ for proton observe and $125.77 \mathrm{MHz}$ for carbon observe. The samples for NMR characterization were dissolved in perdeuterated methanol or perdeuterated dimethyl sulfoxide at a concentration of approximately $1 \sim 4 \mathrm{mg} / \mathrm{ml}$.

For the assignment of both proton and carbon chemical shifts and the elucidation of the molecular structures, a combination of several 1D and 2D NMR-techniques were applied for both of the isolated compounds, 1 and 2 . In both cases, TOCSY ${ }^{4}{ }^{6)}$ with mixing times of $30 \mathrm{~ms}$ and $70 \mathrm{~ms}$ and a conventional COSY with double quantum filtering ${ }^{7)}$ provided an almost complete assignment of all proton resonances. The amino acid protons were assigned on the basis of their unique proton chemical shifts and their characteristic proton coupling patterns.

A proton detected heteronuclear chemical shift correlation (HMQC) experiment was implemented to unambiguously correlate proton and carbon chemical shifts via the $\mathrm{J}_{\mathrm{CH}}$ scalar coupling. Non-protonated carbons were unambiguously assigned by implementing a multiple bond correlation (HMBC). An evaluation of the HMQC spectrum and the HMBC spectrum not only confirmed the proton assignments but also allowed the definitive assignment of both protonated and non protonated carbons. The proton and chemical shifts are given in Tables 1,2 and 3.

\section{Taxonomy of the Producing Strain}

The producing organism, an actinomycete Streptomyces griseus, was originally isolated from soil. This culture, designated as SC488, is deposited in Sterling Winthrop's Culture Collection, Collegeville, PA, USA.

\section{Fermentation of Culture SC488}

All shake-flask fermentations were incubated in a humidified shaker $(75 \%)$ at $27^{\circ} \mathrm{C}$ and $210 \mathrm{rpm}(1$ inch throw). Following incubation at $27^{\circ} \mathrm{C}$ for 7 days on BENNET's agar, a colony was transferred to $30 \mathrm{ml}$ of medium A (in 250 -ml shake-flask) and incubated for 24 hours. Stock vials of frozen mycelium were prepared from this culture by combining $0.5 \mathrm{ml}$ culture with $0.5 \mathrm{ml}$ aqueous lactose/glycerol $(5 \% / 10 \%)$. The vials were preserved at $-70^{\circ} \mathrm{C}$.

Seed cultures for inoculation of production media were typically prepared as follows: a single vial of frozen mycelium was used to inoculate a $250-\mathrm{ml}$ shake-flask containing $30 \mathrm{ml}$ of medium A. After 24 hours, the entire contents of the flask were transferred to a 2.8 -liter Fernbach flask containing $500 \mathrm{ml}$ of medium B, which was then incubated for 48 hours before use as an inoculum for the production medium (medium B). Characteristics of an effective second stage seed culture at 48 hours were $\mathrm{pH} 7.1$ and homogeneous mycelial morphology.

Production of the calpain inhibitors was also accomplished in 5.0-liter bench-top fermentors (BioFlo III, New Brunswick Scientific) in medium B. The actively growing 48 hour second stage seed culture was used as inoculum at a concentration of $10 \%(\mathrm{v} / \mathrm{v}, 500 \mathrm{ml}$ inoculum into a 5.0-liter fermentor). Fermentors were maintained at $27^{\circ} \mathrm{C}$, agitated at $400 \mathrm{rpm}$, and sparged with air at $2.5 \mathrm{liter} /$ minute. The culture was harvested after 72 hours of growth, the $\mathrm{pH}$ at harvest was 7.6. Packed cell volume (PCV) was used to estimate cell mass by centrifugation $(15 \mathrm{ml}$ of whole culture broth for 10 minutes at $3,500 \mathrm{rpm}$ ) and estimating the ratio of cell volume to total volume $(\% \mathrm{PCV}=$ cell volume/total volume $\times 100)$. The $\mathrm{PCV}$ after 72 hours was $20 \%$.

Medium A consisted of ( $\mathrm{g} /$ liter) glycerol (20), dextrin (20), bacto-soytone (10), yeast extract (3), $\left(\mathrm{NH}_{4}\right)_{2} \mathrm{SO}_{4}(2), \mathrm{CaCO}_{3}(2)$; it was adjusted to $\mathrm{pH} 7.0$ before autoclaving.

Medium B consisted of (g/liter) glucose (20) Traders pharmamedia (15), $\left(\mathrm{NH}_{4}\right)_{2} \mathrm{SO}_{4}(3), \mathrm{ZnSO}_{4} \cdot 7 \mathrm{H}_{2} \mathrm{O}$ $(0.03), \mathrm{CaCO}_{3}$ (4) and yeast extract (5).

Analytical Method for Fermentation of Culture SC488

HPLC was used to detect components in the crude fermentation broth which were then assayed in 
the calpain casein assay. A sample of $40 \mu$ of the supernatant from centrifugation of the whole broth (1 to $10 \mathrm{ml}$ ), was injected onto a Rainin Microsorb ODS 4.6 i.d. $\times 150 \mathrm{~mm}$ column. The flow rate was $1 \mathrm{ml} / \mathrm{minute}$, the isocratic solvent system was $30 \%$ methanol and $70 \% 100 \mathrm{~mm}$ ammonium acetate, and the column temperature was maintained at $30^{\circ} \mathrm{C}$.

\section{Extraction of Fermentation Broth}

Cells from the 5 liter fermentations were removed by centrifugation. The clarified broth (approximately 4 liters) was combined with approximately $300 \sim 400 \mathrm{~g}$ HP-20 resin. The slurry was gently stirred for five minutes and the supernatant removed by filtration. The loaded resin was washed with two volumes of water, and active material eluted using 1.5 volumes of acetone. The solvent was removed in vacuo at $25^{\circ} \mathrm{C} \sim 30^{\circ} \mathrm{C}$ to yield $8 \mathrm{~g}$ of a brown gum.

\section{Isolation of Compounds 1 and 2}

The extract was re-dissolved in a solvent mixture containing $5 \%$ methanol in water and loaded onto a C-18 column $(2.5 \mathrm{~cm} \times 30 \mathrm{~cm})$. The column was eluted with a step gradient of methanol and water at a flow rate of $10 \mathrm{ml} / \mathrm{minute}$. All fractions were assayed in the calpain casein assay and the most active one (fraction C, $400 \mathrm{mg}$ ), was further separated on a Waters Delta Preparative HPLC system using a Waters 1000 Prepak column at a flow rate of $100 \mathrm{ml} /$ minute. The solvent system used was a mixture of two solvents designated as $\mathrm{A}$ and $\mathrm{B}$. The concentration of $\mathrm{A}$ in the various steps is indicated and the concentration of $\mathrm{B}$ is obtained as follows: $100 \%$-concentration of $\mathrm{A}$. The solvent gradient system was as follows: $10 \% \mathrm{~A}$ to $15 \% \mathrm{~A}$ in 50 minutes, $15 \% \mathrm{~A}$ to $100 \% \mathrm{~A}$ in 15 minutes, where $\mathrm{A}=2: 1 i-\mathrm{PrOH}$ - acetonitrile and $\mathrm{B}=0.1 \%$ TFA in water. Column effluents were monitored by a UV detector at $220 \mathrm{~nm}$ collecting $50 \mathrm{ml}$ fractions. All fractions were assayed in the calpain casein assay and the active ones analyzed by HPLC. Fractions No. $68 \sim 72$ were found to be active $\left(\mathrm{IC}_{50}=0.8 \mu \mathrm{M}\right.$ ) and were combined (compound $1,8 \mathrm{mg}$ ). Active fractions No. $103 \sim 104(7 \mathrm{mg})$ were also combined and further purified using a C-18 column with the following solvent gradient: $15 \% \mathrm{~A}$ in 10 minutes, $15 \% \mathrm{~A}$ to $30 \% \mathrm{~A}$ in 50 minutes, $30 \% \mathrm{~A}$ to $80 \% \mathrm{~A}$ in 2 minutes, $80 \% \mathrm{~A}$ in 2 minutes, where $A=0.1 \%$ TFA in acetonitrile, and $B=0.1 \%$ TFA in water; the concentration of $B$ is obtained as follows $B=100 \%$-concentration of $A$, flow rate $=10 \mathrm{ml} /$ minutes. Pure compound $2(2 \mathrm{mg})$, was obtained with an $\mathrm{IC}_{50}=2.1 \mu \mathrm{M}$.

Physical and Spectroscopic Data of Compounds 1 and $\mathbf{2}$

1: colorless oil; ${ }^{1} \mathrm{H}$ and ${ }^{13} \mathrm{C}$ NMR, Table 1; IR $(\mathrm{KBr}) \mathrm{cm}^{-1} 3345,2946,2834,1630$ and 1122; HRFAB-MS, calculated for $\mathrm{C}_{20} \mathrm{H}_{22} \mathrm{~N}_{2} \mathrm{O}_{4}+\mathrm{H}=$ 355.1658 , found 355.1657 ; UV $\lambda_{\max } 226(480), 278$ (96).

2: white solid; $\mathrm{mp} 159 \sim 160^{\circ} \mathrm{C} ;{ }^{1} \mathrm{H}$ and ${ }^{13} \mathrm{C}$ NMR: Tables 2 and 3, respectively; IR $(\mathrm{KBr}) \mathrm{cm}^{-1}$ $3520 ; 3300,3045,1690$ and 1620; HRFAB-MS, calculated for $\mathrm{C}_{29} \mathrm{H}_{40} \mathrm{~N}_{4} \mathrm{O}_{7}+\mathrm{H}=557.2975$, found 557.2978; UV $\lambda_{\max } 228(7740), 278(2684) \mathrm{nm}$; CD $\max ^{\mathrm{m}} 230.8 \mathrm{~nm}[\theta]$ (53 960), $\min ^{\mathrm{m}} 216.2$ (127 946), $\left[\alpha_{\mathrm{D}}\right]^{20}-30.2^{\circ}(c 1.0, \mathrm{MeOH})$.

Determination of the Stereochemistry of Compounds 1 and 2

The stereochemistry of compounds $\mathbf{1}$ and $\mathbf{2}$ was determined by a chemical method consisting of derivatizing the amino acids with MARFEY's reagent $^{8)}$.

A $5 \mu \mathrm{mol}$ sample of 1 , was mixed with $1 \mathrm{ml}$ of $6 \mathrm{~N}$ hydrochloric acid and stirred at $120^{\circ} \mathrm{C}$ for 3

Table $1 .{ }^{13} \mathrm{C}$ and ${ }^{1} \mathrm{H}$ NMR assignments of 1 in methanol- $d_{4}$.

\begin{tabular}{lrl}
\hline \multicolumn{1}{c}{ Carbon $\mathrm{No}$} & ${ }^{13} \mathrm{C} \delta(\mathrm{m})$ & ${ }^{1} \mathrm{H} \delta$ \\
\hline $\mathrm{N}_{1}-\mathrm{CH}_{3}, \mathrm{~N}_{4}-\mathrm{CH}_{3}$ & $34.46(\mathrm{q})$ & $2.78(3 \mathrm{H}, \mathrm{s})$ \\
2,5 & $168.35(\mathrm{~s})$ & \\
3,6 & $65.90(\mathrm{~d})$ & $4.09(1 \mathrm{H}, \mathrm{dd}, 4.2,6.4)$ \\
$7,7^{\prime}$ & $30.45(\mathrm{t})$ & $2.75(1 \mathrm{H}, \mathrm{dd}, 4.2,14.2)$ \\
& & $2.14(1 \mathrm{H}, \mathrm{dd}, 6.4,14.2)$ \\
$8,8^{\prime}$ & $129.33(\mathrm{~s})$ & \\
9,$13 ; 9^{\prime}, 13^{\prime}$ & $132.27(\mathrm{~d})$ & $6.91(2 \mathrm{H}, \mathrm{d}, 6.4)$ \\
10,$12 ; 10^{\prime}, 12^{\prime}$ & $117.18(\mathrm{~d})$ & $6.73(2 \mathrm{H}, \mathrm{d}, 6.4)$ \\
$11,11^{\prime}$ & $158.46(\mathrm{~s})$ & \\
\hline
\end{tabular}

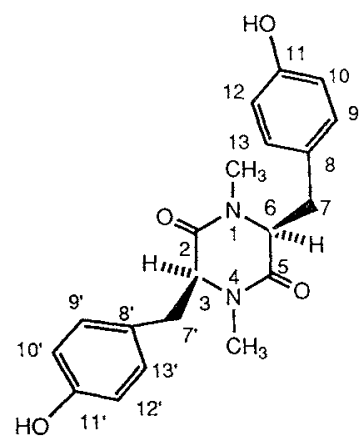


Table 2. ${ }^{1} \mathrm{H}$ NMR assignments of $\mathbf{2}$ in methanol- $d_{4}$ and dimethyl sulfoxide- $d_{6}$.

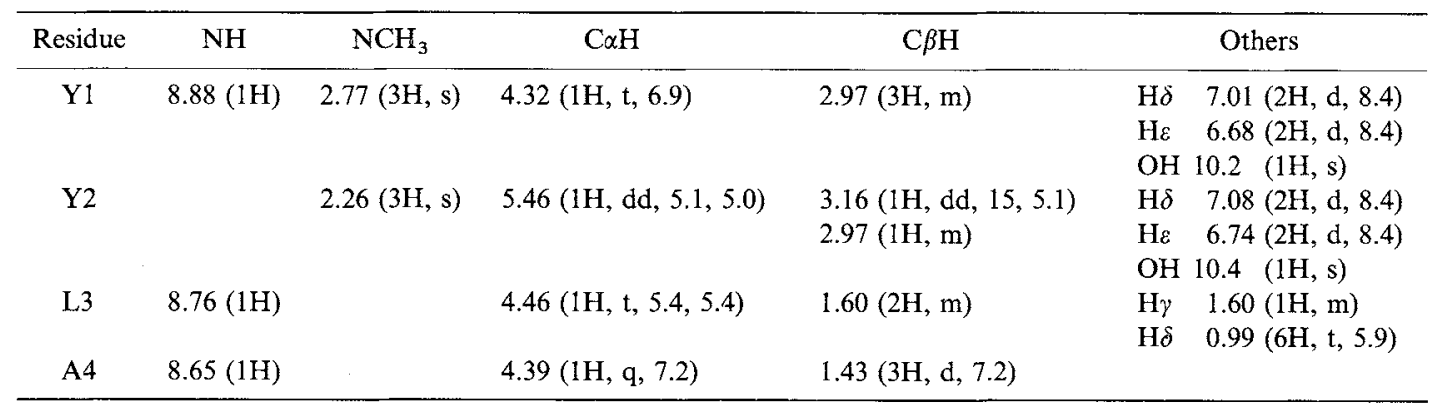

Where: $\quad \mathrm{Y}_{1}=$ terminal $N$-methyltyrosine, $\mathrm{Y}_{2}=N$-methyltyrosine, L3=leucine, $\mathrm{A} 4=$ alanine.

hours. The sample was dried, neutralized with sodium bicarbonate and reacted with a $1 \%$ solution of MARFEY's reagent (1-fluoro-2,4 dinitrophenyl-5L-alanine amide) in acetone, The reaction mixture was stirred at $40^{\circ} \mathrm{C}$ for a day and analyzed using a Beckman C-18 HPLC ultrasphere column at a flow rate of $1 \mathrm{ml} /$ minute. The solvent gradient system used was as follows: $5 \% \mathrm{~A}$ to $50 \% \mathrm{~A}$ in 30 minutes, where $A=$ methanol and $B=0.02 \mathrm{M}$ sodium acetate $\mathrm{pH} 4$, the concentration of $\mathrm{B}$ is obtained as follows: $\mathrm{B}=100 \%-$ concentration of $\mathrm{A}$, detector at $340 \mathrm{~nm}$. A $5 \mu \mathrm{mol}$ solution of $\mathrm{L}-\mathrm{N}$-methyltyrosine used as a standard, was also reacted with MARFEY's reagent ( $1 \%$ solution in acetone) and analyzed using the same HPLC column and conditions described for the hydrolyzed peptide.

A $5 \mu \mathrm{mol}$ sample of $N$-methyltyrosyl- $N$-methyltyrosyl-leucyl-alanine (2), was hydrolyzed with hydrochloric acid and derivatized with MARFEY's reagent as described above for the diketopiperazine of $N$-methyltyrosine. Commercially available amino acids of $\mathrm{L}$ - $\mathrm{N}$-methyltyrosine, L-leucine, D-leucine, L-alanine and D-alanine were also reacted with a $1 \%$ solution of MARFEY's reagent in acetone. The derivatives obtained from both the standard and the hydrolyzed peptide were analyzed on a Beckman column with the following solvent gradient system: $10 \% \mathrm{~A}, 20 \% \mathrm{~B}$ and $70 \% \mathrm{C}$ in 60 minutes, $10 \% \mathrm{~A}, 20 \% \mathrm{~B}$ and $70 \% \mathrm{C}$ to $25 \% \mathrm{~A}, 25 \% \mathrm{~B}$ and $50 \% \mathrm{C}$ in 20 minutes, $25 \% \mathrm{~A}, 25 \% \mathrm{~B}$ and $50 \% \mathrm{C}$ in 10 minutes, where $\mathrm{A}=$ methanol, $\mathrm{B}=$ acetonitrile and $\mathrm{C}=0.02 \mathrm{M}$ sodium acetate $\mathrm{pH} 4$, flow rate $=1 \mathrm{ml} /$ minute, detector $340 \mathrm{~nm}$.

\section{Synthesis of Compound 2}

$N$-Methyltyrosyl- $N$-methyltyrosyl-leucyl-alanine 2, was synthesized using standard solid phase methodology ${ }^{9)}$ on a Boc-Ala-4-chloromethyl resin (Merrifield Resin, Biosearch). Amino acids were added as the $t$-butoxycarbonyl (boc) derivatives and the hydroxyl group of the $N$-methyltyrosine residue was protected as the 2,6-dichlorobenzyloxycarbonyl derivative (diClBzl). Boc-Leu-OH (5 mmol, Bachem) was coupled to the resin using benzotriazolyloxytetramethyluronium hexafluorophosphate (HBTU, $5 \mathrm{mmol}$ ) and diisopropylethylamine (DIEA, $15 \mathrm{mmol}$ ) in $N, N$-dimethylformamide for 16 hours. After this period, boc- $N$-methyltyrosine protected as the diClBzl $(2.5 \mathrm{mmol})$ was added with bromo-tris-pyrrolidinophosphonium hexaffuorophosphate (PyBrop, $2.5 \mathrm{mmol}$, Calbiochiochem) and DIEA ( $7.5 \mathrm{mmol})$ in $N, N$-dimethylfomamide for 24 hours.

Cleavage from the resin support was accomplished by adding $15 \mathrm{ml}$ of a cleaving solution ( $30 \mathrm{ml}$ TFA, 
$17 \mathrm{ml}$ dimethyl sulfide, $6 \mathrm{ml} \mathrm{m}$-cresol and $10 \mathrm{~g}$ trifluoromethanesulfonic acid) and stirring for 4 hours. The cleaving mixture was filtered, partitioned with diethyl ether $(300 \mathrm{ml})$ and the $\mathrm{pH}$ adjusted to a range between $5 \sim 7$ with $1 \mathrm{~N} \mathrm{NaOH}$. The aqueous layer was partitioned with ether and neutralized again, the process being repeated until the ether layer was clear.

The peptide was purified using a Waters Delta Preparative HPLC system and a Vydac C18 Delta Prep Pak column at a flow rate of $100 \mathrm{ml} /$ minute. The solvent gradient system used was as follows: $0 \% \mathrm{~B}$ to $40 \% \mathrm{~B}$ in 40 minutes, $40 \% \mathrm{~B}$ to $100 \% \mathrm{~B}$ in 10 minutes, where $\mathrm{A}=0.1 \%$ TFA in water and $\mathrm{B}=0.1 \%$ TFA in acetonitrile, the concentration of $B$ is obtained as follows $B=100 \%$-concentration of $A$.

Calpain, ${ }^{3} \mathrm{H}$-casein Assay

Culture extract and resulting fractions were dissolved in dimethyl sulfoxide or a solution consisting of $50 \%$ methanol in water until a final assay solvent concentration of $1 \%$. In the presence of purified human $\mathrm{RBC}^{10)}$ calpain $\left(0.73 \mu \mathrm{g} /\right.$ tube), the hydrolysis of $\left[\right.$ acetyl $\left.{ }^{3} \mathrm{H}\right]$ casein was inhibited by bioactive fractions. The assay substrate was $0.1 \mathrm{mg} / \mathrm{ml}$ casein: $0.096 \mathrm{mg} / \mathrm{ml}$ of unlabeled casein and $0.004 \mathrm{mg} / \mathrm{ml}$ of ${ }^{3} \mathrm{H}$-casein with a specific activity of $22.5 \mathrm{mCi} / \mathrm{g}$.

The uncleaved substrate was precipitated using trichloroacetic acid and the soluble tritiated fragment was quantitated by scintillation counting. Assay inhibition by active fractions was calculated as a percent of the total hydrolysis in the absence of an inhibitor.

\section{Results and Discussion}

The diketopiperazine of $N$-methyltyrosine 1, was isolated from the solid phase HP-20 extract of the microbial broth using flash chromatography followed by preparative HPLC. This compound displayed inhibitory activity against calpain $\left(\mathrm{IC}_{50}=0.8 \mu \mathrm{M}\right)$. High resolution $\mathrm{MS}$ indicated a molecular formula of $\mathrm{C}_{20} \mathrm{H}_{22} \mathrm{~N}_{2} \mathrm{O}_{4}$. In the UV spectrum, bathochromic shifts from $226 \mathrm{~nm}$ to $244 \mathrm{~nm}$ and from $278 \mathrm{~nm}$ to $294 \mathrm{~nm}$ were observed after $\mathrm{NaOH}$ addition suggesting the presence of a phenolic functionality.

The presence of ${ }^{1} \mathrm{H}$ NMR signals at $\delta 6.91(\mathrm{~d}, J=6.4 \mathrm{~Hz})$ and $6.73(\mathrm{~d}, J=6.4 \mathrm{~Hz})$, two corresponding ${ }^{13} \mathrm{C} \mathrm{NMR}$ signal at $\delta 132.27(\mathrm{C} 9)$ and $117.18(\mathrm{C} 10)$, and two non-protonated $s p^{2}{ }^{13} \mathrm{C}$ resonances at $\delta 129.33$ and 158.46 indicated a 4-substituted phenol moiety. In the ${ }^{1} \mathrm{H}$ NMR spectrum geminal methylene protons at $\delta 2.75$ and 2.14 were coupled to each other $\left(\mathrm{J}_{\text {geminal }}=14.2 \mathrm{~Hz}\right)$ and further coupled to a methine at $\delta 4.09$. The methylene protons are attached to $\mathrm{C} 7$, while the methine proton to the chiral $\mathrm{C} 6$. The remaining structural features deduced from NMR spectra include a singlet for the $N$-methyl group $\left({ }^{1} \mathrm{H} \delta 2.78\right.$ and $\left.{ }^{13} \mathrm{C} \delta 34.46\right)$ and an amide carbon $\left({ }^{13} \mathrm{C} \delta 168.35\right)$.

The above structural features and the molecular formula indicated that this molecule is a diketopiperazine condensed from two $N$-methyltyrosine units. Amino acid analysis confirmed that in fact the only amino acid present in this compound was $N$-methyltyrosine. Derivatization with MARFEY's reagent established the $\mathrm{L}$ configuration at the chiral center since the retention time of the peak corresponding to the derivatized compound obtained from the microbial broth was identical to the retention time of a commercially available sample of L- $N$-methyltyrosine that had been previously derivatized with MARFEY's reagent. When both compounds were co-injected, they also afforded a single peak.

A second active compound (2) with an $\mathrm{IC}_{50}=1.2 \mu \mathrm{M}$ was also isolated from the HP-20 extract using reverse-phase flash and preparative HPLC. HRFAB-MS indicated a molecular formula of $\mathrm{C}_{29} \mathrm{H}_{40} \mathrm{~N}_{4} \mathrm{O}_{7}$, consistent with the proposed structure of compound 2. MS data (FAB, DCI) further supported the presence of two contiguous $N$-methyltyrosine units $(\mathrm{Y} 1-\mathrm{Y} 2)$ and fragments corresponding to 355 Daltons were found in FAB and DCI spectra.

The ${ }^{1} \mathrm{H}$ NMR spectrum revealed 4 signals between $\delta 4 \sim 5.5$ corresponding to the $\alpha$ hydrogens of the 
amino acids (Y1, Y2, L3, A4). The two $N$-methyltyrosine residues could be distinguished on the basis of unique spin systems and coupling constants. Thus, the methine proton of terminal $N$-methyltyrosine (Y1) at $\delta 4.32$ was coupled to two $\mathrm{H}_{\beta}$ protons at $\delta 2.97$, while the methine proton of internal $N$-methyltyrosine (Y2) at $\delta 5.46$ was coupled to protons $\beta_{1}$ and $\beta_{2}$ at $\delta 3.16$ and 2.97 respectively (numbering system of compound 2 indicated in Fig. 1). It is interesting to note that the $\alpha$ proton of the internal $N$-methyltyrosine (Y2) exhibited an unusual low field chemical shift at $\delta 5.46$. The steric effect of the $N-\mathrm{CH}_{3}$ in $\mathrm{Y} 2$ may cause 2 to adopt a conformer in which the $\mathrm{H} \alpha$ of $\mathrm{Y} 2$ is deshielded by the amide carbonyl group of $\mathrm{Y} 1$. Additional COSY correlations were observed in the leucine and alanine residues such as the $\alpha$ proton on leucine coupled to the methylene protons and the $\alpha$ proton on alanine coupled to the methyl group. $\mathrm{C}-\mathrm{H}$ correlations that were established from HMQC and HMBC NMR data also supported the presence of these 4 amino acid moieties.

Amino acid analysis yielded $N$-methyltyrosine, leucine and alanine in a $2: 1: 1$ ratio confirming the structural feature for compound 2. Amino acid sequencing using Edman degradation clearly established the following structure: $N$-methyltyrosyl- $N$-methyltyrosyl-leucyl-alanine and the linearity of the peptide. The stereochemistry of each amino acid was determined to be $L$ from amino acid analysis with MARFEY's reagent. Under the HPLC conditions described in Materials and Methods, the commercially available L and $\mathrm{D}$ amino acids eluted at the following retention times: $\mathrm{L}$-alanine at 9.5 minutes, $\mathrm{D}$-alanine at 21 minutes; L-leucine at 51 minutes, D-leucine at 81 minutes; L- $N$-methyltyrosine at 15 minutes. The hydrolyzed $N$-methyltrosyl- $N$-methyltyrosyl-leucyl-alanine yielded peaks at retention times of $9.5,15$, and 51 minutes corresponding to those from L-alanine, L- $N$-methyltyrosine and L-leucine respectively. To confirm the structure of compound $\mathbf{2}$, as well as its absolute stereochemistry, the compound was synthesized by solid phase synthesis using as coupling reagents $\mathrm{HBTU}^{11)}$ for $\mathrm{NH}$-amino acids and $\mathrm{PyBrop}{ }^{12,13)}$ for $\mathrm{N}$-methylated amino acids. The synthetic peptide had a ${ }^{1} \mathrm{H}$ NMR spectrum, MS spectrum, optical rotation, CD spectrum and HPLC profile identical with those of the isolated compound.

To summarize, two new inhibitors of calpain were isolated from microbial broth SC488: a diketopiperazine of $\mathrm{N}$-methyltyrosine and a tetrapeptide containing $\mathrm{N}$-methyltyrosine. Low molecular weight peptidyl calpain inhibitors such as leupeptin, antipain and $\mathrm{E} 64^{14)}$ have been previously reported and even some calpain inhibitors containing tyrosine ${ }^{2)}$, but none containing $N$-methyltyrosine. The structures presented here represent new variations on peptides reported as calpain inhibitors.

\section{Acknowledgments}

The authors are grateful to M. Doleman, C. Emery, E. Wanner, H. Wolfe, L. Musza, L. N. Reuss, D. Antonacci, Susan Stahly, G. C. Kydd, M. Olsen, R. E. Dolle for their technical assistance. Also, we thank Panlabs, Inc. for initial isolation and screening of the SC488 strain and to M. RoGERs from M. Scan Inc. for HR-MS data.

\section{References}

1) Tsujinaka; T.; Y. Kajiwara, J. Kambayashi, M. Sakon, N. Higuchi, T. Tanaka \& T. Mori: Synthesis of a new cell penetrating calpain inhibitor (calpeptin). Biochem. Biophys. Res. Commun. 153: 1201 1208, 1988

2) Ogura, K.; M. Maeda, M. Nagai, T. Tanaka, K. Nomoto \& T. Murachi: Purification and structure of a novel cysteine proteinase inhibitor strepin P-1. Agric. Biol. Chem. 49: 799 805, 1985

3) Pontremoli, S.; E. Melloni \& B. L. Horecker: Current topics in cellular regulation: Modulation by covalent modification. Ed., S. Shaltiel, vol 27, pp. $293 \sim 303$, Head Press, 1985

4) ERnSt, R. R. \& L. BRAUnSChweIleR: Coherence transfer by isotopic mixing: Application to proton correlation spectroscopy. J. Magn. Reson. 53: 521 528, 1983 
5) BAX, A.; R. A. BYRD \& A. Aszalos: Spin multiplet enhancement in two-dimensional correlated NMR spectroscopy. J. Am. Chem. Soc. 106: 7632 7633, 1984

6) BAX, A. \& D. G. Davis: HLEV-17-Based two dimensional homonuclear magnetization transfer spectroscopy. J. Magn. Reson. 65: 355 360, 1985

7) Piantini, U.; O. W. SOREnSEn \& R. R. ERnst: Multiple quantum filters for elucidating NMR coupling networks. J. Am. Chem. Soc. 104: 6800 6801, 1982

8) Szokan, G.; G. Mezo, F. Hudez, Z. Majer, I. Schon, O. Nyeki, T. Szirtes \& R. Dolling: Racemization analyses of peptides and amino acid derivatives by chromatography with pre-column derivatization. J. Liq. Chromatogr. 12: 2855 2875, 1989

9) Erickson, B. W. \& R. B. Merrifield: The Proteins. Ed., H. Neurath et al., vol. 2, pp $257 \sim 527$, Academic Press, 1976

10) Gopalakrishna, R. \& S. H. BarSKY: Hydrophiobic association of calpains with subcellular organelles. J. Biol. Chem. 261: $13936 \sim 13942,1986$

11) Dourtoglou, V.; J. C. Ziegler \& B. Gross: L' Hexafluorophosphate de O-benzotriazolyl-N,NTetramethyluronium: un reactif de couplage peptidique nouveau et efficace. Tetrahedron Lett. 1978: 1269 1272, 1978

12) Coste, J.; E. Frerot \& P. Jouin: Oxybenzotriazole free peptide coupling reagents for N-methylated amino acids. Tetrahedron Lett. 32: 1967 1970, 1991

13) Dourtoglou, V. \& B. Gross: O-Benzotriazolyl-N,N, $N^{\prime}, N^{\prime}$-tetramethyluronium hexafluorophosphate as coupling reagent for the synthesis of peptides of biological interest. Synthesis 1984: $572 \sim 574,1984$

14) Angliker, H.; J. Anagli \& E. SHaw: Inactivation of calpain by peptidyl fluoromethyl ketones. J. Med. Chem. 35: $216 \sim 220,1991$ 